\title{
RAMP UP AND RAMP DOWN DYNAMICS IN DIGITAL SERVICES
}

\author{
HENK AKKERMANS \\ Tilburg University
}

\author{
CHRIS VOSS D \\ The University of Warwick \\ ROELAND VAN OERS \\ Tilburg University
}

\begin{abstract}
Volume ramp ups are notoriously difficult in digital services, where market pressures can lead to ramping up too soon and too rapidly which in turn can lead to the need to ramp down. This paper addresses the challenge of taking innovation to scale in an established firm by enhancing our understanding of the nature of service ramp ups and ramp downs. Digital service ramp ups differ substantially from production ramp ups as the speed is much greater, and problems are visible to customers. However there are similarities between service ramp downs and product recalls and an important contribution is exploring the nature of ramp downs their processes and possible causes. Using an engaged research approach, longitudinal data from three consecutive ramp ups in a European telecom operator were collected. Through analyses of cases, qualitative and quantitative case data, and using a system dynamics model, we identified a set of issues that affect service ramp ups and ramp downs. These include the need to ramp up the service supply chain, biases leading to unrealistic assumptions about scalability and problem-solving, decision biases in various functions, launching digital services in beta form, a lack of transparency of capacity and lack of learning from previous ramp ups. We show that if these problems are not addressed or resolution is delayed, this can lead to cycles of delay, backlogs and productivity problems and the inevitability of a ramp down. We explore reasons and importance for such delays that lead to service ramp downs.
\end{abstract}

Keywords: service supply chains; ramp ups; ramp downs; recalls; system dynamics; clinical methods; engaged research

\section{INTRODUCTION}

Nobody has been as fast as we intend to be. (Ramp up manager)

\footnotetext{
Acknowledgments: The authors would like to thank those associated with ETEL over the period of this research, in particular Annelore Buijs, Eric Kuisch, and Willem van Oppen, for their support and invaluable insights.

The copyright line for this article was changed on March 11, 2019 after original online publication.
}

\footnotetext{
Markets are pressuring companies to develop new services quickly and to get them to market as soon as possible, leading to pressure for rapid deployment and ramp ups. Such pressure has increased with the growing digitalization of service sectors such as banking, insurance, and media (McKinsey \& Co., 2015). Ramp ups of such services usually require a significant commitment of resources, which may cause problems if the available resources do not match the demand growth or if they are diverted from other services and involve ramping up the whole service supply chain.
} 
One of the top five reasons for new product and service failures is organizations failing to manage the ramp up (Schneider \& Hall, 2011). Problems during ramp up can lead to difficulties in meeting time-to-market targets and may negatively influence service outcomes. For example, following an SAP rollout by an energy provider in 2011, many of the company's 5.4 million customers experienced issues, such as billing delays as account details were transferred to the SAP platform. A resulting backlog of complaints created longer call-waiting times. The UK energy regulator highlighted a serious deterioration in service levels (Finnegan, 2013), prompting a public apology from the CEO. A public sector example is the rollout of the US Affordable Care Act (Obamacare). In 2013, former Secretary of Health and Human Services, Kathleen Sebelius, said that the administration's original predictions about its timetable were "flat-out wrong." She remarked, "Could we have used more time and testing? You bet" (Alter, 2014). This created problems for both the potential users and the government. Negative publicity around repeated problems with new service and system ramp ups is not uncommon, with numerous examples of rapid ramp ups and a pattern of initial rapid rollouts followed by ramp downs - a slowdown or complete halt.

There is extensive literature on the need for product and service innovation, such as new service development (NSD) and the processes involved (Menor, Tatikonda \& Sampson, 2002). However, this literature is virtually silent on the challenge of taking innovation to scale. In this paper, we focus on this challenge in service firms, specifically in the context of digital services. The effectiveness of ramp ups can be an important factor in competitiveness. The competitive advantage gained from knowledge-based assets, such as new services, depends in part on exploiting them effectively via rapid and effective ramp up and doing so consistently better than one's competitors. Thus, it is important for managers in service organizations to understand the issues, key decisions, and trade-offs associated with ramp ups and how any problems can be mitigated during the ramp up process. Equally, at a theoretical level, we need to develop a better understanding of the nature of service ramp ups. Research into digital service supply chains has shown how unforeseen problems can lead to the phenomenon of fallout (Akkermans \& Vos, 2003). Scalability is an important aspect of service ramp ups, both the nature of the service and management assumptions affect it (Boyer, Hallowell \& Roth, 2001; Hallowell, 2001).

The research in this paper set out to explore ramp ups in the context of digital services. As the research progressed, we observed problematic ramp ups leading to ramp downs and extended the scope of the research to address this. There is a growing body of ramp up research in manufacturing (Heine, Beaujean
\& Schmitt, 2016; Terweisch, Bohn \& Chew, 2001) and the supply chain (Li, Shia, Gregory \& Tan, 2014). We contend that the context of services, in particular digital services, can differ substantially from products during ramp ups. We put forward and explore three areas of difference. First, service ramp ups take place in the field, and as production and consumption are simultaneous, they may manifest themselves directly to the customer in setup or use. Second, in services, especially digital services, ramp ups can be much steeper. Finally, there can be pressures to ramp up the service before it is fully developed. In addition to differences, there are commonalities between product and service ramp ups, especially in that both require ramping up the supply chain resources and capacities. Ramp downs have not been studied, though product recall, which has similar characteristics, is an area of increasing concern to supply chain managers and researchers (Wowak \& Boone, 2015). The objective of this paper is to explore ramp ups and ramp downs in the context of digital services, which we address through longitudinal field research in three digital services in a medium-sized European telecom company.

This paper contributes to knowledge on the challenge of taking innovation to scale in an established firm by enhancing our understanding of the nature of service ramp ups, ramp downs, and associated issues. A distinctive contribution of this research is identifying the importance and the nature of the ramp down stage and associated decisions and issues.

\section{LITERATURE REVIEW}

\section{Service and Product Ramp ups}

A service ramp up is the process of rapidly increasing the delivery of a service to meet demand. The terms "deployment," "launch," and "rollout" are frequently used to describe the same activities. Existing knowledge on ramp ups is primarily based on products, "the notion of ramp ups has never been used in the case of services" (Lenfle \& Midler, 2009, p. 158). There are a range of factors that potentially affect product ramp up success, including product complexity and scope, project management, quality of the manufacturing process (Clark \& Fujimoto, 1991), learning prior to and during ramp up (Pisano, 1996), and running pilot production and full-scale ramp up in parallel (Terweisch et al., 2001). The dynamic context of ramp ups means that many decisions must be made quickly. The ability to act is influenced by high levels of multidisciplinarity, with decision makers from different fields such as production, logistics, or planning. Their actions may interact, creating interdependencies (Rössler, 2016). This complexity of ramp ups can lead to a low degree of transparency, complicating the decision-making process (Brauner et al., 2016). 
Design schedule slippage can cause ramp ups to be accelerated to meet delivery targets, leading to huge budget and schedule overruns, described as "train wrecks" (Mass \& Berkson, 1995). Moreover, the increasing levels of automation in the service processes of digital services give rise to the possibility of "order fallout." For example, quality problems often occur in service supply chains, especially when they are under pressure (Oliva \& Sterman, 2001); if the problem cannot be addressed by IT, it "falls out" and requires manual intervention, sometimes called "rework" (Akkermans \& Vos, 2003). Backlogs resulting from fallout can lead to high workloads, more errors, and more rework, triggering a vicious cycle of more errors, rework, and work pressure. This can lead to high uncertainty concerning future capacity requirements.

Products and services are increasingly linked, both conceptually and through design. An example is servitization, where manufacturers develop the capabilities needed to provide services that supplement their traditional product offerings (Baines, 2015). The extant research on product ramp ups is relevant to services, but the nature of services - especially digital services during ramp up-may lead to differences from product ramp ups. First, product ramp ups take place in the factory, whereas service ramp ups take place in the field. In services, problems during ramp up will not only lead to delays, but as production and consumption are simultaneous, problems may manifest directly to the customer in setup or use. In contrast, many problems that occur in product ramp ups may not be visible to customers beyond delivery delays, and they may allow problem-solving and learning to take place prior to delivery to customers (Terweisch et al., 2001).

Another potential difference between products and services is the speed of ramp up. As companies look beyond time-to-market to time-to-volume, the speed of ramp up has become increasingly important (Terweisch et al., 2001). Although there are equal pressures on products and services to get innovations to market rapidly, in services, especially digital services, where IT lead times can be extremely short, ramp ups can be much steeper. The steeper the ramp up, the less time there is to detect and react to problems before they affect a large customer base.

An important antecedent of the ability to ramp up rapidly is scalability: the ability of a system, network, or process to handle a growing amount of work in a capable manner or enlarged to accommodate that growth. The scalability of the service itself is a measure of how it scales when deployed on larger and/or more systems or as more load is applied. Boyer et al. (2001) described a continuum from high to low scalability in services. Services that are pure information have high scalability, and commoditized and standardized services exhibit higher scalability, while more unique or awkward handling issues exhibit lower scalability. Hallowell (2001) argued that scalability is often neglected when firms seek to maximize the growth of technologically intermediated services. To achieve high scalability, firms seek to reduce their dependence on human resources through automation. This approach can have severe limitations, such as when the physical components associated with the service do not lend themselves to high scalability (Boyer et al., 2001).

There are issues associated with overly rapid product/service development. The "get big fast" strategy is associated with the growth of the Internet and digital business; it is widely accepted that getting big too fast can be dangerous, and there are limits to growth (Sterman, Henderson, Beinhocker \& Newman, 2007). Setting aggressive commercialization schedules often has the opposite effect than intended, creating longer delays and lower quality, with cascading effects on product development projects (Mass \& Berkson, 1995). Too rapid growth also contributes to the erosion of service quality, for example, by hiring inexperienced employees. This leads to productivity fall-offs, the diversion of experienced personnel to support this, excessive workloads, and subsequent employee burnout and, ultimately, to even worse service quality.

Ramp ups must be managed throughout the supply chain (Li et al., 2014). A service supply chain is where service providers draw on the resources of diverse subcontractors, including internal suppliers, and integrate those resources into the production of the service (Maull, Geraldi \& Johnston, 2012; Sampson \& Spring, 2012). Elements of service components can also be delivered to the customer directly from the subcontractor (Wynstra, Axelsson \& van der Valk, 2006). Conceptualizations of service supply chains stress the interconnected relationships among customers, service providers, and their subcontractors (Selviaridis \& Norrman, 2014). The process of creating and defining value is not as straightforward since multiple actors, including the customer, are involved in service design, production, and delivery. When a complex service is ramped up, there is an implicit assumption that all components of the service, including the upstream service supply chain, can be ramped up at the same rate or already have the capacity in place.

As service ramp ups typically take place at the end of the NSD process, the nature and outcome of this process may affect ramp up success. In services, this development process commonly involves two phases: alpha and beta. The objective of the alpha phase is to improve the quality of the service and ensure that it is ready for final development. Testing takes place when the service is in a near-fully usable state and is 
normally performed by test engineers and "friendly users." Most known critical issues should be fixed at this stage. The beta phase takes the nearly usable service and develops it into a service that is ready for release. Testing takes place in the "real world" with real customers, and feedback can cover every element of the service, typically involving the full service team, including marketing, support, quality, and engineering personnel. The beta phase is considered closed and ready for launch when all major and minor issues have been addressed. Commercial pressures to launch early, combined with the difficulty of fully testing a service before ramp up, can lead to a product or service being released before it is fully developed. There is evidence that it is increasingly common for services to be launched before being fully tested -"launching in beta" (Zomerdijk \& Voss, 2011).

Although the phenomenon of service ramp downs has not been studied, it may have similarities to product recalls. There are growing numbers of recalls, particularly in products such as automotive and pharmaceutical where defective products have the potential to cause harm (Ball, Shah \& Donohue, 2018; Hora, Bapuji \& Roth, 2011). Causes of the need to recall can include design defects, manufacturing defects, inadequate testing, or inadequate or misleading instructions for use (Hall \& Johnson-Hall, 2017; Hora et al., 2011). Of concern in product recalls is the time taken to recall (Ni \& Huang, 2017). The decision to recall may be voluntary, initiated by the supplier, or involuntary, required by a regulatory body. Product recall costs, which can be considerable, are pressing concerns for supply chain managers (Wowak \& Boone, 2015). Hora et al. (2011) point out that in addition to the societal costs of recalls, firms face their own external failure costs, both direct and indirect, that arise from product recalls. Direct costs include the costs of managing the reverse flow of products, disposal costs, restitution costs, and legal and liability costs due to any litigation. Indirect costs, which in some instances may be higher than direct costs, include loss of brand image and erosion of market value.

\section{Research Objectives}

At the outset of this research, the objective was to develop our understanding of service ramp ups. Ramp ups remain a relatively understudied area; "while researchers have studied product development processes, relatively few studies directly address new product launch" (Schoenherr \& Swink, 2015, p. 901), and extant research has focused on product but not on service ramp ups. As the research progressed, we observed problems during ramp up leading to major ramp downs, which made us extend our objectives to include developing understanding of the nature and process of service ramp down. Given the paucity of research into both service ramp ups and ramp downs, to improve knowledge and understanding, especially in the case of digital services, we needed to build on extant research from products but recognize potential differences. To do so, we needed to explore the antecedent processes, dimensions, and outcomes of service ramp ups and ramp downs. Areas highlighted by previous research include scalability, ramping up the supply chain, and managerial behavior with respect to the speed of ramp up and timing of ramp down. The above review suggests that the scope of study should include both the antecedents and the supply network of the services studied. As the ramp up and ramp down processes extend over a period of time, a longitudinal research process is appropriate.

\section{METHOD}

The research is based on a longitudinal study of three cases embedded in a single company using an engaged research process (Van de Ven, 2007). The research was conducted at ETEL, a medium-sized European telecommunications provider. This industry involves frequent ramp ups of new services, which are early in product life cycles, with increased demand for on-time deliveries in shorter time frames and generally shorter lead times (Agrella, Lindroth \& Andreas Norrman, 2004, p. 2). These services are increasingly digitally based, and thus, the industry is an appropriate setting for this study. ETEL was chosen because two of the authors were already conducting research there.

For research in emergent areas and theory development, inductive methods using a limited number of cases are appropriate (Barratt, Choi \& Li, 2011). A longitudinal research design (Åhlström \& Karlsson, 2016) is appropriate for examining processes that unfold over time. Taking the service ramp up as our unit of analysis, we selected three consecutive cases of ramp ups embedded in one company. When selecting cases, it is also important to consider the parameters that will be held constant across the sample (Voss, Johnson \& Godsell, 2016). The selected cases all had similar organizational contexts, markets, technologies, and market pressures for rapid ramp up.

Case 1 (2005-2007) entailed the launch of Consumer Voice over Internet Protocol (VOIP). A key objective was to provide superior services over its existing infrastructure, keeping its market-leading customer base intact. At the outset of the study, ETEL was suffering at the hands of cable operators offering higher speeds using new technology. Thus, ETEL wanted to upgrade its old-fashioned copper infrastructure to fiber and sell the new service to as many people as possible, which constitutes case 2 (2007-2009): fiber-based broadband services. Following consumer 
VOIP, the company launched a business VOIP service - case 3 (2010-2011). In all three cases, a key goal was to roll out the new service as fast as possible, either to preempt or react to the competition. Because of their strategic importance, there were effectively no budget constraints.

\section{Data Collection $^{1}$}

In longitudinal studies, the main method of data collection is participant observation, where the researcher records actions as they occur in the research setting. A clinical research process was used (Karlsson, 2016), supplemented by case research methods in case 2. Clinical research is an established engaged method in social sciences where the organization invites the researcher to examine and contribute to understanding and addressing an important problem or set of problems. It typically involves a research question that is of interest to both the researcher and the organization (Karlsson, 2016; Schein, 1987). In this study, the case company invited one of the coauthors to study and address the problems associated with the ramp up of a new service. Schein (1987) argued that there are four possible modes for clinical enquiry: pure enquiry, diagnostic enquiry, actionoriented enquiry, and confrontive enquiry. This research followed the diagnostic and action-oriented enquiry modes. The purpose of diagnostic enquiry is searching for causalities, and for action-oriented enquiry, it is influencing the organization's thought process in regard to actions in the past, present, and future (Karlsson, 2016, p. 281).

One researcher had a continuous relationship with the organization and kept a logbook of all the interactions with the company. In addition to the direct interactions, the researcher had access to substantial documentation and company databases. In case 1, as part of developing an understanding of the causalities, a system dynamics-type cause-and-effect model was developed (Sterman, 2000), and four workshops were held with a set of managers from the organization and the associated supply chain to discuss the conceptual structure of the model. At the end of the first case, the developed understandings and model were discussed with the leadership of the ramp up process. These led to action by the company in seeking to improve their processes. Based on the learning from case 1, the data needed to be collected for the second case to enable understanding of the ramp up were identified. The process the researcher used was repeated for the second ramp up. The cause-and-effect model was developed further to reflect the findings from the second case. Again, a workshop was held

${ }^{1}$ Further details of the data collection are available in our online supplement. with company managers, which also led to improvement action by the company. At the end, the research and top management reflected on the experience, the findings, and the learning for future ramp ups. A similar process was conducted for case 3 .

Additional data in case 2 were collected by a second author using case research rather than clinical research. Twenty interviews were carried out with company managers, with 13 conducted in case 2 and seven after the ramp down in case 3 . The model developed in the previous case provided initial guidelines for the research. A simple protocol was used for the interviews (e.g., "What went wrong? Why did it go wrong?"). All the interviews were recorded in the local language and transcribed, and their durations lasted 45-90 minutes in length.

Sources of data in longitudinal research should include interviews and documents (Åhlström \& Karlsson, 2016), yielding both qualitative and quantitative data (Voss et al., 2016). Quantitative data on all three ramp ups were collected from company records and databases on sales, orders at various process stages, rework rates, backlogs, and call and complaint rates over the ramp up period. Qualitative data were gathered from interviews, attendance at meetings, and archival material. The researchers also had access to the company's intranet database. Analysis was based on a combination of the clinical and case research data. Management decisions were annotated using archival meeting records and presentations ( $\sim 700$ archive records), and some 180 separate events were distilled. For each case, a narrative or story of how the sequence of events produced the outcome was constructed. Timelines were developed for each ramp up, identifying key issues and decisions at points along the timeline. The data were coded using the relational database functionality of Excel. An iterative process was followed to search for patterns, commonalities, and differences across the cases, which were then reviewed with the research team and company managers for refining and further development. For crosscase analysis, the timeline patterns and key themes were compared across the three cases. This research design provides strong situational grounding and enhances the quality and depth of insights in emergent areas, but it has limitations in terms of generalizability (Ketokivi \& Choi, 2014).

To address reliability and validity, a range of people involved in decision-making were interviewed, and results were fed back to participants (Voss et al., 2016). A senior manager responsible for large parts of the services participated in discussions and reflections on what had taken place in all three ramp ups. The iterative collection of data from different sources provided multiple triangulation opportunities, enhancing reliability and validity (Barratt et al., 2011). 
TABLE 1

Summary of In-case Analysis

\begin{tabular}{|c|c|c|c|}
\hline & Case 1: Consumer VOIP & Case 2: Fiber broadband & Case 3: Business VOIP \\
\hline \multicolumn{4}{|l|}{ Alpha Phase } \\
\hline Alpha testing & $\begin{array}{l}\text { Test on small number of } \\
\text { customers }\end{array}$ & $\begin{array}{l}\text { Limited number of friendly } \\
\text { users }\end{array}$ & $\begin{array}{l}\text { Extended period of } \\
\text { testing with } 100 \\
\text { friendly users }\end{array}$ \\
\hline $\begin{array}{l}\text { Orders taken } \\
\text { during alpha } \\
\text { phase }\end{array}$ & No orders taken & Orders taken during phase & No orders taken \\
\hline \multicolumn{4}{|l|}{ Beta Phase } \\
\hline $\begin{array}{l}\text { Orders taken } \\
\text { during beta } \\
\text { phase }\end{array}$ & $\begin{array}{l}\text { Public launch and orders } \\
\text { taken, limited ramp up } \\
\text { already started }\end{array}$ & $\begin{array}{l}\text { Increasing number of orders } \\
\text { taken. Pressure to increase } \\
\text { sales }\end{array}$ & Limited order intake \\
\hline Beta testing & Test on users & $\begin{array}{l}\text { Tested on large number of } \\
\text { users }\end{array}$ & Test on users \\
\hline $\begin{array}{l}\text { Problems during } \\
\text { phase }\end{array}$ & $\begin{array}{l}\text { Technical problems with } \\
\text { service connectivity }\end{array}$ & $\begin{array}{l}\text { Many technical problems } \\
\text { leading to lack of } \\
\text { activation, workarounds }\end{array}$ & $\begin{array}{l}\text { Technical problems, } \\
\text { many addressed } \\
\text { through workarounds }\end{array}$ \\
\hline $\begin{array}{l}\text { Problems at end } \\
\text { of phase }\end{array}$ & Some intermittent service & Many problems remaining & $\begin{array}{l}\text { Problems perceived as } \\
\text { solved }\end{array}$ \\
\hline $\begin{array}{l}\text { Backlog and } \\
\text { capacity issues } \\
\text { at end }\end{array}$ & $\begin{array}{l}\text { No supply chain capacity } \\
\text { problems, some backlog }\end{array}$ & $\begin{array}{l}\text { Significant backlog and } \\
\text { capacity issues }\end{array}$ & Almost no backlog \\
\hline $\begin{array}{l}\text { Ramp up } \\
\text { escalation }\end{array}$ & $\begin{array}{l}\text { Rapid ramp up of sales } \\
\text { efforts }\end{array}$ & Rapid ramp up of orders & Ambitious ramp up \\
\hline $\begin{array}{l}\text { Issues during } \\
\text { ramp up }\end{array}$ & $\begin{array}{l}\text { More complex orders } \\
\text { added } \\
\text { Technical problems }\end{array}$ & $\begin{array}{l}\text { Activations lag orders } \\
\text { Technical problems } \\
\text { Capacity problems }\end{array}$ & $\begin{array}{l}\text { New problems emerge } \\
\text { Workarounds not } \\
\text { robust }\end{array}$ \\
\hline & $\begin{array}{l}\text { Fulfillment capacity } \\
\text { shortage }\end{array}$ & Backlog worsens & $\begin{array}{l}\text { Rapid backlog growth } \\
\text { Problems in part of } \\
\text { service not involved in } \\
\text { beta testing }\end{array}$ \\
\hline \multicolumn{4}{|l|}{ Ramp down } \\
\hline $\begin{array}{l}\text { Weeks from ramp } \\
\text { up to start of } \\
\text { ramp down }\end{array}$ & 32 weeks & 11 weeks & 11 weeks \\
\hline Triggered by & $\begin{array}{l}\text { Level of complaints } \\
\text { Negative media coverage }\end{array}$ & $\begin{array}{l}\text { High backlog, quality } \\
\text { problems, and level of } \\
\text { complaints }\end{array}$ & $\begin{array}{l}\text { Massive backlog } \\
\text { Order cancelations }\end{array}$ \\
\hline $\begin{array}{l}\text { Degree of ramp } \\
\text { down }\end{array}$ & $\begin{array}{l}\text { Rapid slowing of order } \\
\text { intake }\end{array}$ & All order intake stopped & $1 / 3$ of orders canceled \\
\hline
\end{tabular}

\section{ANALYSIS}

The qualitative data for the three ramp ups are shown in Appendix and summarized in Table 1. In all three, the supply chains were a combination of service, IT, and physical elements. An overview of the supply chain for case 1 is shown in Figure 1.

Cross-case analysis found that all three cases showed similar patterns of ramp up behavior (see Figures 2-4) - development followed by rapid ramp up and, after problems developed, ramp down. For example, in case 1 , once a sale had been made (contracted), installation and activation were required before the customer can use the service. When backlogs or post-installation problems occurred, customers contacted the helpdesk, who also registered complaints. While installation was not delayed, as the supply chain was able to cope with the growth in contracts, there were problems in using the installed services, leading to an escalation in calls to 
FIGURE 1

Case 1 Service Supply Chain [Color figure can be viewed at wileyonlinelibrary.com]

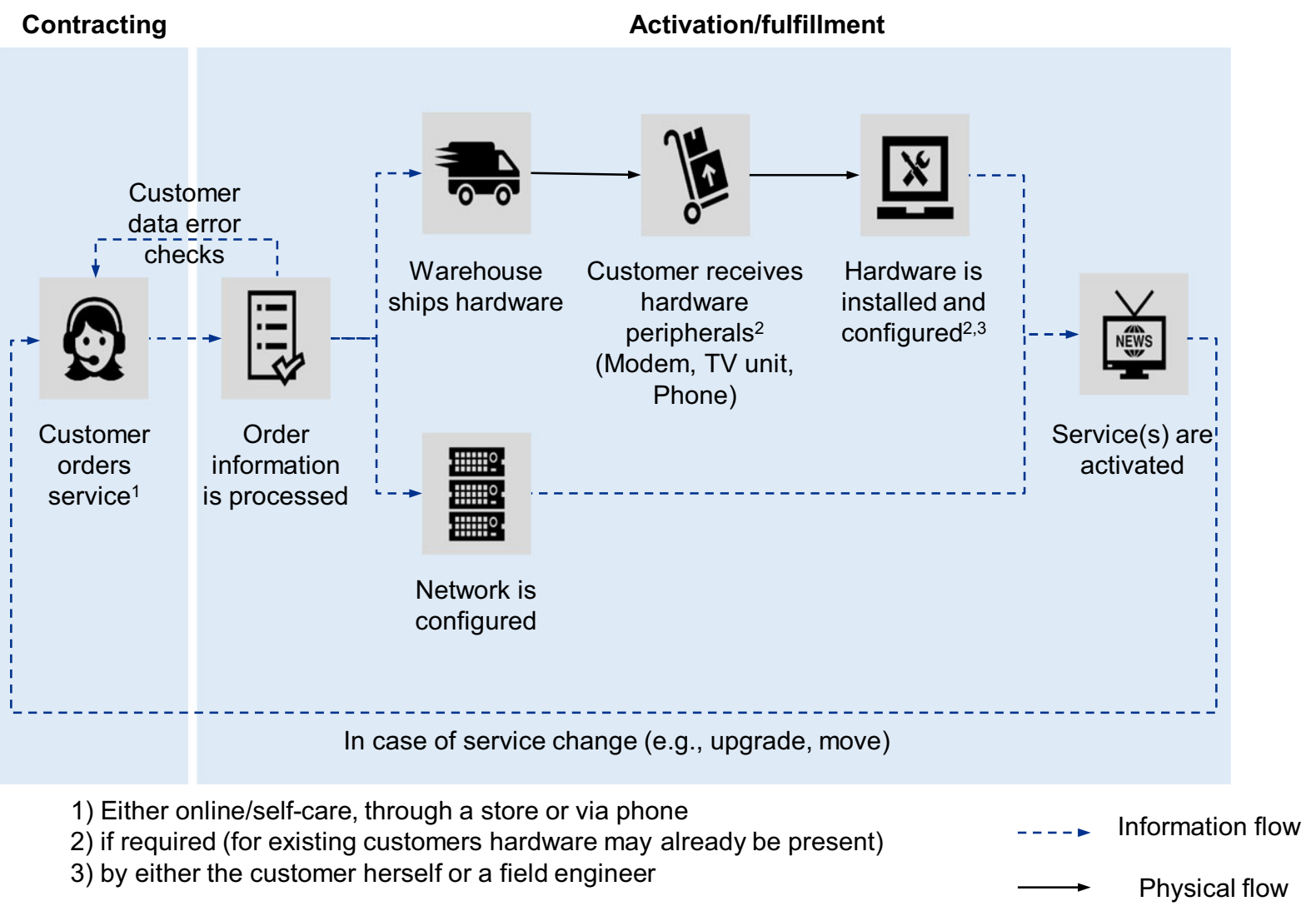

the contact center and, in turn, an escalation in complaints. Figure 2 shows the data for the rapid growth of contracted sales, growth of complaints pending, and rapid growth of helpdesk call volume.

Activation lagging behind sales created a backlog (cumulative orders contracted less orders activated). This is illustrated by cases 2 and 3: Problems during ramp up meant that, although orders were taken, installation (and therefore activation) was delayed. Figure 3 shows the resulting dramatic rise in backlog in case 2. Figure 4 shows the same pattern for case 3 as well as the resulting order cancelations. One striking feature was the extent of the ramp down. In all three cases, when the level of backlog and/or complaints eventually became extremely high, the company had to stop, slow, or cancel order intake, leading to ramp down.

We analyze the data across the three cases in two phases, ramp up and ramp down. We then model the dynamics of the interactions between marketing and operations to gain further insights into the ramp up and ramp down processes.

\section{Ramp up}

Alpha Phase. In this phase, the service was tested with limited use. For example, in case 2, testing was initially conducted internally and then with a number of friendly users, followed by a first local pilot. In case 3 , testing was extended to 100 friendly users. This phase generated considerable feedback, which informed problem-solving and refinement. In all three cases, there were explicit strategies for restraining growth, but there were actual initial sales in cases 1 and 2.

Beta Phase. In this phase, further development of the service was ongoing, with a strong focus on problem-solving, learning, and resolving all problems so that full ramp up could proceed. Sales began with real rather than friendly customers to enable beta testing of the service in the delivered mode. In cases 1 and 2, the level of order intake, although low, was higher than desired by the technical teams; problems with delivery and use led to increased backlogs and negative customer feedback. No formal beta testing took place before the decision was made to ramp up; 
FIGURE 2

Case 1 Timeline [Color figure can be viewed at wileyonlinelibrary.com]

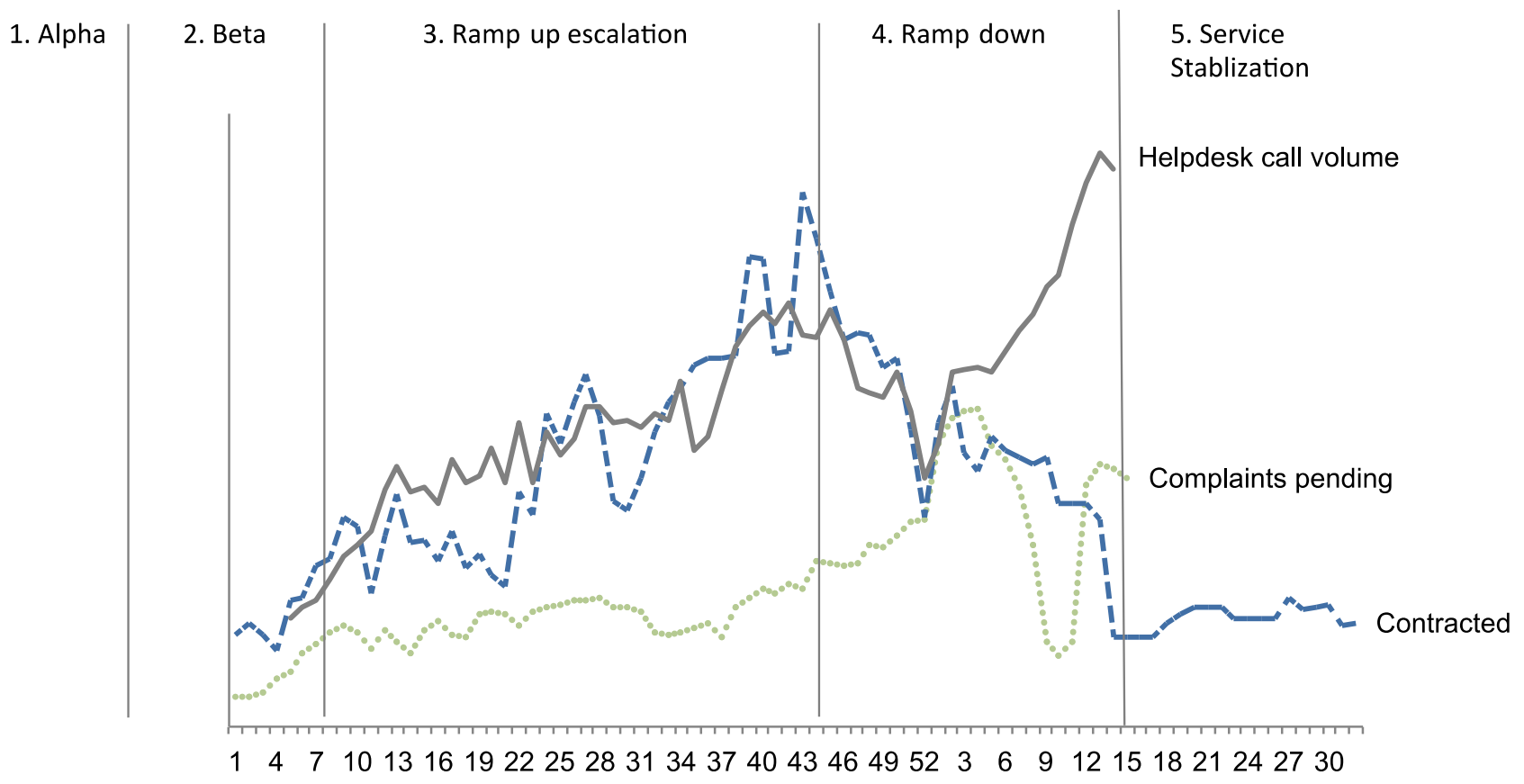

FIGURE 3

Case 2 Timeline [Color figure can be viewed at wileyonlinelibrary.com]

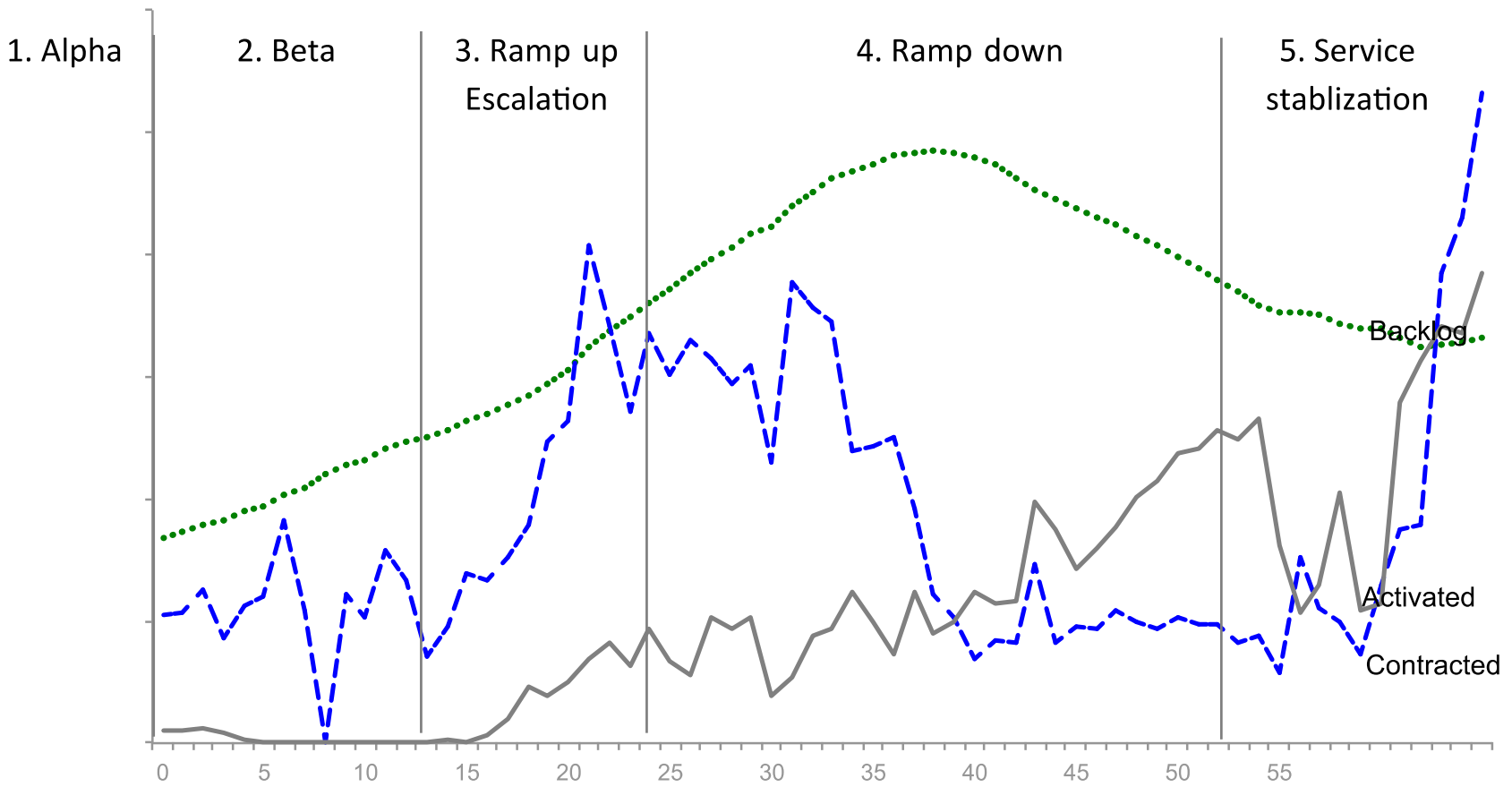

although many problems remained unsolved or the solutions were workarounds, it was decided to execute a very rapid ramp up. In effect, in cases 1 and 2, the service was launched in beta. In case 3, management decided not to launch in beta and felt that all problems had been addressed. However, only the upstream 
FIGURE 4

Case 3 Timeline [Color figure can be viewed at wileyonlinelibrary.com]

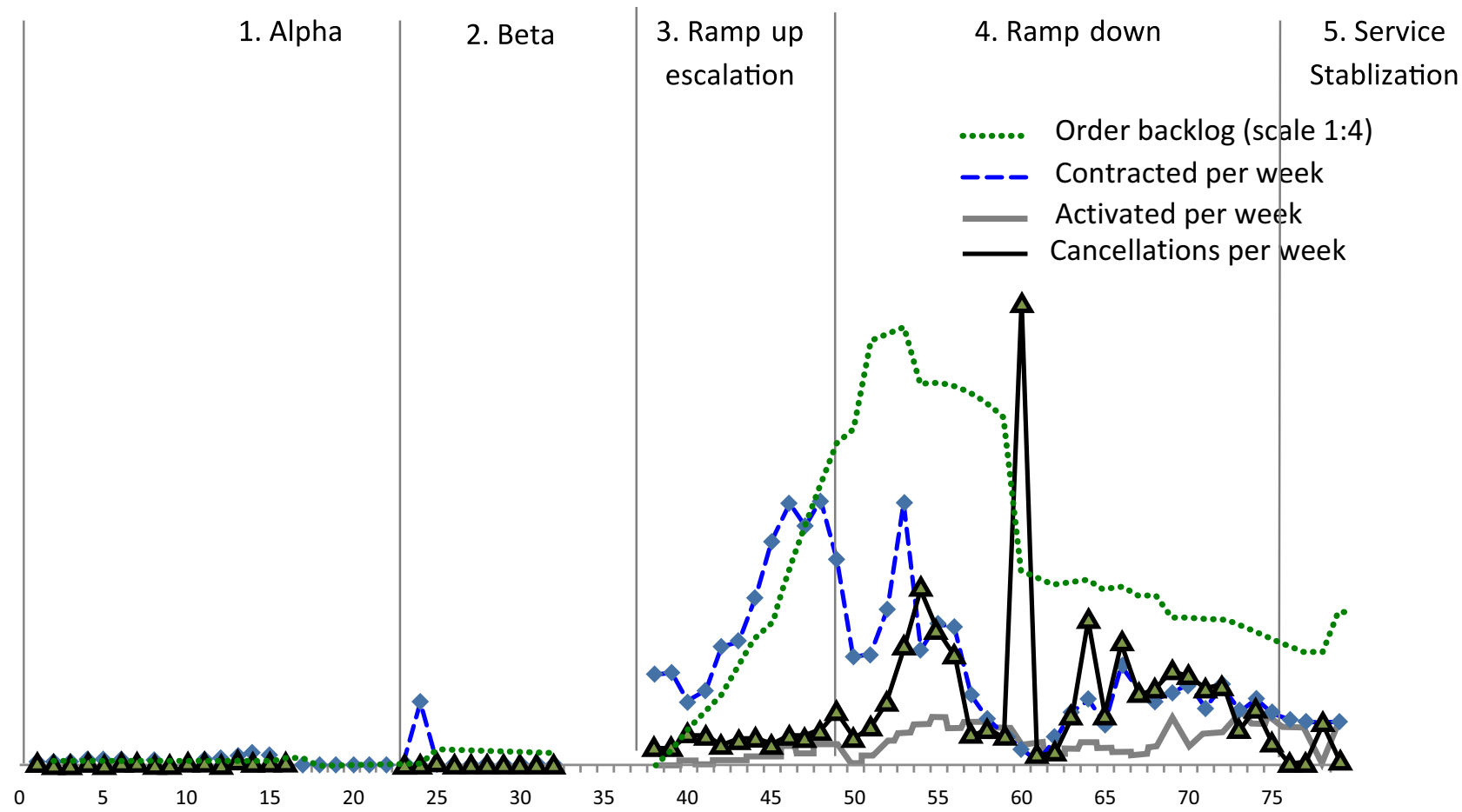

service supply chain had been tested, not the downstream activities.

Ramp up Escalation. In all three cases, sales effort was increased dramatically. The demand for all three services was high, and the sales teams were successful in meeting their aggressive sales targets. In cases 1 and 2, despite testing, unanticipated problems occurred during scale-up, delaying activations and leading to a huge increase in the order backlog (see Figure 3). In case 1 , the delay in acquiring and deploying resources to address customer problems led to a rapid growth in complaints (see Figure 2). In all three cases, various efforts were made during this period to resolve problems and ensure that activations and problem-free use were back on track.

ETEL's management was aware of the potential pitfalls of ramping up too quickly and the importance of building an effective cross-functional sales and operations planning process (Oliva \& Watson, 2011). They sought to learn from both ongoing and previous failed ramp ups, to avoid repeating earlier mistakes. However, despite the steps taken to preempt such issues, all three ramp ups were problematic, raising the question of how effective the learning was from case to case. We next explore this in the context of two important decisions, when to ramp up and how fast to scale up the service.

\section{Ramp up Decisions}

Prelaunch. Given the competitive pressure for early launch and rapid ramp up in combination with uncertainty over technical issues, deciding when and how aggressively to ramp up is crucial. In cases 1 and 2 , the decision was made to ramp up early, in particular launching took place before beta testing was complete. This is consistent with previous research (Zomerdijk \& Voss, 2011) indicating that this is common when there are strong market pressures and fully testing a service before launch may be difficult and slow. The greater the pressure to get to market before competitors, the greater the likelihood that decisions will be made to ramp up before the firm is ready to do so-increasing the risk of order fallout and resulting cycles of delay, backlog, and productivity problems. There was a clearly understood risk that early ramp up could lead to problems, despite this the company ramped up early assuming that these problems would be addressed. Ramp up escalation was driven by commercial pressure, which could have blinded marketing to the reality of the ramp up problems. In cases 2 and 3, although the activation rates increased slowly, no management action was taken to reduce the pressure on sales. This may have been due in part to the lack of visibility of both activation rates and backlogs. These decisions could also be explained 
as a result of the planning fallacy (Buehler, Griffin \& Ross, 1994), the tendency to optimistically plan project timescales and resources and to overlook project risks. This is one manifestation of the optimism bias: a cognitive bias leading people to think they are more likely to succeed, or are less at risk of failure or of experiencing a negative event, than they really are. "Planners tend to overestimate the probability of the successful completion of a project and underestimate the probability of negative events, overspends, and setbacks. Moreover, this occurs even when knowing that the majority of similar projects have over-run" (Behavioural Insights, 2017, p. 5). A service such as this draws on the resources of diverse subcontractors, including internal suppliers (Sampson \& Spring, 2012). Thus, the decision on when to ramp up should also address availability of resources and the readiness of the supply chain. The data from cases 1 and 2 indicate that this was inadequate and a contributor to ramping up too early.

Ramping up early led to predictable negative outcomes. Technical or design problems occurred during ramp up and post-ramp up use. When problems occur in use that cannot be dealt with easily, resolving the ensuing phenomenon of "order fallout," discussed earlier, often requires substantial human resources. In digital services, this can lead to a cycle of unexpected and sharp workload increases in the problem-solving and customer-handling areas (Akkermans \& Vos, 2003). This was evident in the negative outcomes; for example, dealing with the problems in case 1 led to a major workload increase in both problem- and complaint-handling, leading to further delays and backlogs.

Postlaunch. A second key decision is the speed of ramp up. In all three cases, consistent with previous research (Mass \& Berkson, 1995), our data indicated that the rapid ramp up caused problems. The speed of ramp up is linked to scalability. Two factors that can limit scalability are the non-IT elements of the service and the complexity of the service (Boyer et al., 2001; Hallowell, 2001), these were evident in all three cases, thus limiting the scaling of the services.

We observed that scalability encompassed two areas: scalability of the supply chain and scalability of the service. Problems with the scalability of the supply chain were most apparent in case 2, where the rapid ramp up required scaling up of capacity in multiple locations. All cases illustrated problems with the scalability of the service. In case 1 , the initial version of the service was designed for simple-use contexts, and it did not scale up well for more complex uses. The service still being in beta at the start of the ramp up compounded the scaling problems. This was also a problem in case 2, where the immaturity of the software led to increasingly more IT workarounds. In case
3, the service was not ramped up until the company was confident that it was working well. However, this testing was limited to the upstream order-handling. Downstream, a multitude of smaller orders was all interdependently executed by a wide variety of independent internal and outsourced units. As a result, the service soon encountered a multitude of technical problems and delays.

In all three cases, management, despite knowing in advance about the risks of ramping up too fast, decided to ramp up early and to ramp up very rapidly. This raises the question of: Why? The planning fallacy (Buehler et al., 1994) is one explanation of management's behavior. They may also have ramped up too quickly because of a lack of understanding of the constraints of scalability. Despite there being a spectrum of scalability, from high to low (Boyer et al., 2001), their behavior is consistent with assuming that the scalability is much higher that should be expected from the service context (Hallowell, 2001). This was compounded by a failure to recognize the complexity of the service supply chainindeed, as one senior manager at ETEL stated, "We have no supply chain."

We conclude that unrealistic expectations of scalability due to the planning fallacy and a lack of attention to and understanding of the scalability of both the service and the supply chain contributed significantly to decisions to accelerate ramp up speed, leading to the experienced ramp up problems.

\section{Capacity Management}

The operations management team were set a target of 100 percent utilization of all resources. In a volatile context, a conservative approach to setting capacity levels can lead to a lack of flexibility in dealing with extra capacity demands, limiting rapid response capability. For example, in case 1, the problems led to a quadrupling of capacity in the call centers along with 300 additional installation technicians and a new team to deal with complex complaints individually. These resources took considerable time to be deployed.

Capacity problems persisted throughout the ramp ups. In case 2, both the JV partner and the pool of engineers reported that they would be unable to deliver sufficient manpower to meet the demand plan. By the end of the beta phase, in case 2, the fiber management team proposed that they should execute a "commercial emergency brake" as there was no evidence that the supply network could handle the required numbers. In response to their statement that "it will be impossible to meet this deadline given the current resources," management replied, "Make it possible." Marketing wrongly assumed that the service supply chain could cope with a rapid ramp up (up to 160 
times the volume) and that capacity build-up would not be an issue: "We then believed the network would go live very quickly" (Marketing manager, case 2). In cases 2 and 3, the complexity of the service supply chain was underestimated, leading to difficulties in implementing robust demand and capacity systems before full ramp up. Case 2 involved a complex service, requiring many steps to be taken in harmony by multiple independent parties in synchronizing activities as diverse as digging to place cables and installing software upgrades for communication with new equipment. New reporting methods also had to be implemented, making it problematic to assess actual delivery performance for the current pool of orders, and, as a result, the service supply chain lacked transparency.

\section{Ramp down}

Corrective efforts were insufficient to reduce the backlogs or levels of customer problems in the short term. In case 1, there was major public discontent; in cases 2 and 3, management came to realize that the backlog of contracted customers waiting to be activated had become excessive, lead times were too long, and quality problems and complaints were at unacceptably high levels. In all three cases, management drastically curtailed the order intake, and in case 3, they even canceled a large part of the backlog (Figure 4). Following ramp downs, management focused on solving the main service problems to ready the company for renewed ramp ups, which were more cautious and conservative. An important but neglected decision area is whether, when, and how to ramp down. We examine the empirical data to explore why they occurred, why and when decisions to ramp down were made, and how they were handled.

The antecedents of the ramp downs arose from the factors described in the previous section: ramping up while still in beta, ramping up very fast, and failing to manage the scaling of the service and the supply chain. These led to problems that needed to be addressed, and the longer such problems went unsolved, the greater the probability that there would be a need for a major ramp down. In all the cases, there was failure to fully resolve the problems quickly. We observe a number of possible reasons for this. First, as in case 1, when problems did occur, there were insufficient resources to address them as they occurred, and there was a time lag in mobilizing sufficient resources. Second, time pressure meant that problems were addressed through a range of fixes, technical compromises, and workarounds "We continue to connect small batches of customer and commercial testing to facilitate learning in operations and support a quick ramp up when the supply chain is fully ready" (Management presentation, case 2). In case 2, workarounds were already being used in the alpha phase: "What doesn't work will be solved with workarounds" (Management team presentation, case 2). Just prior to the ramp down, the company was managing about 30 workarounds, ranging from simple to complex, costly, and time-consuming solutions. Gross (2014) observed in product launches where unexpected problems occur, these need to be addressed as soon as they arise, leading to improvisational behavior, workarounds. This decreases both the launch performance and financial performance, and thus, improvisation should be avoided during new product development as well as during the launch. He also argued that this could be a source of valuable learning in regard to new problems and their solutions. There is thus a trade-off between solving problems permanently, which may slow down ramp ups, or hoping that workarounds will lead to problems being fully addressed before there is market damage and potentially ramp down.

The above led to a situation where problems could likely not be resolved rapidly and where there would be negative customer impact. However, the time taken to decide to ramp down seemed to be slow, for case 1 it was 32 weeks (see Table 1), though faster subsequent reactions indicate that learning may have taken place. Cases 1 and 2 in particular indicate that there were delays in making the ramp down decision. We see evidence of a number of possible causes for this. First is lack of, or lack of visibility of, appropriate data to indicate that there were serious current or potential problems. In cases 1 and 2 in particular, although problems were evident at an early stage to those delivering the ramp up, the problems and the signals that there were problems, such as low levels of activation, high levels of backlog and customer complaints, were not necessarily reaching those with decision-making powers concerning ramp up and ramp down. For example, in case 1 , senior management was celebrating record sales at the point when customer complaints were peaking.

Why were the ramp downs needed? Studies on product recall indicate that voluntary recalls take place when there are potentially significant costs of not recalling - societal costs, direct costs, and indirect costs (Hora et al., 2011). In none of the cases were there societal costs, but failure to ramp down may already have led to potentially significant direct costs and loss of revenue, and indirect costs, such as brand image and erosion of market value. There were already significant negative impacts on the customers and hence implications for profit and reputation, and these would have got worse if action were not taken. In case 1 , failures in activation led to a massive rise in customer complaints. In cases 2 and 3, there were major increases in customer backlogs, which in turn led to 
customer complaints and in case 3 to order cancelations by both customers and ETEL. The need for a ramp down occurred when the negative outcomes would be compounded by continued delivery or rollout of the service.

What triggered the decision to ramp down? It is interesting to note that in all three cases ramp downs were not triggered by the initial recognition that there were potentially difficult-to-address problems, although there was ample evidence of such problems occurring and the growth of unplanned backlogs. While these may have raised managerial awareness, it would seem that the decision to ramp down was made only after customer-based feedback. This included increasing customer complaints, order cancelations, and, in case 1, negative social media and television coverage. For example, in case 1, customer problems featured in several programs on national $\mathrm{TV}$, prompting the CEO to state, "We became victims of our own success." If decisions had been made earlier to slow or halt ramp up to allow the issues at hand to be addressed more effectively, the longer-term ramp ups may have been more successful.

To summarize, our observations indicate that there are similarities between service ramp downs and product recall. Whether and when to recall a product is one of the most important, yet complex decisions that an operations manager may face (Ball et al., 2018). Recalls and ramp downs are needed when a point is reached where continued ramp up of the service or use of the product will lead to negative outcomes. There is concern about the time it takes for product recalls to happen, which parallels our case data indicating that the services should have been ramped down earlier. We observe that launching in beta and ramping up rapidly contribute to the problems that trigger the subsequent need to ramp down. This was compounded by the time needed to put in place the resources to deal with the problems and improvisational problem-solving. Moreover, we observe a number of factors that contributed to delaying the decision to ramp down, including optimism bias and lack of visibility of key indicators, such as backlogs and customer complaints, as well as pressure from financial incentives. After these aggressive launches under technical uncertainties, it is unlikely that the ramp downs could have been avoided. However, through more thorough problem-solving, better data visibility, and rapid decision-making there could have been gentler and earlier ramp downs, which could have led to reduced costs to the company.

\section{Learning and Ramp downs}

It could be argued that if the company had learned from the problems in each case, then the problems that led to ramp down subsequent cases may not have occurred. Learning is important in ramp ups (Pisano, 1996), and the longitudinal study gave us the opportunity to examine the learning from case to case. The first opportunity for learning from problems was the ramp up for case 1, which led to development of improved sales and order planning systems. However, no connection seems to have been made between launching early and technical problems in the installation, resulting in the early launch in case 2. By case 3, all these issues had been recognized and steps are taken to address them. Despite this learning, a new set of problems arose from scaling up the service. The workshops held during the ramp ups were specifically designed for learning (Vennix, 1996) and would have provided management with the opportunity to debate and learn from failure (Canon \& Edmonson, 2005); moreover, the involvement of the researchers would have resulted in greater learning than would otherwise have taken place. However, in case 2, it seems that not all this learning was taken on board. This may have been due to the financial and market pressures from senior management as well as optimism bias. In contrast, the learning was taken on board for case 3. Although learning from failure is an obvious thing for an organization to do, there is evidence that it is difficult and often does not occur. A study of a European telecom organization comparable to our case concluded that the company "learned surprisingly little from the failures we investigated. Managers generally explained away large failures on the basis of general societal trends or the involvement of outsiders" (Baumard \& Starbuck, 2005, p. 294). To learn from failure or major problems, companies must first learn to identify failure, not just large-scale, but especially the small failures, and then use analysis to capture the lessons (Canon \& Edmonson, 2005). We conclude that in ramp ups, identifying and learning from problems are important for improving the ramp up process but that there are barriers to this process. In addition, even when there has been valuable learning, it must be recognized that new problems can arise.

\section{Modeling the Dynamics}

So far, we have treated the decisions to ramp up or to ramp down as separate decisions. They take place at different moments in time, but are they two very different decisions? They are taken by the same people, both in sales and in operations, and are based on the same performance indicators. Only the direction of the decisions is completely opposite for ramp ups and ramp downs. A system dynamics analysis can deepen our understanding of these decisions. In all the cases, interaction between operations and marketing/sales functions was both essential and problematical. In each case, based on the observed behavior, 
FIGURE 5

Service Ramp ups and Ramp downs-Three Interconnected Feedback Loops [Color figure can be viewed at wile yonlinelibrary.com]

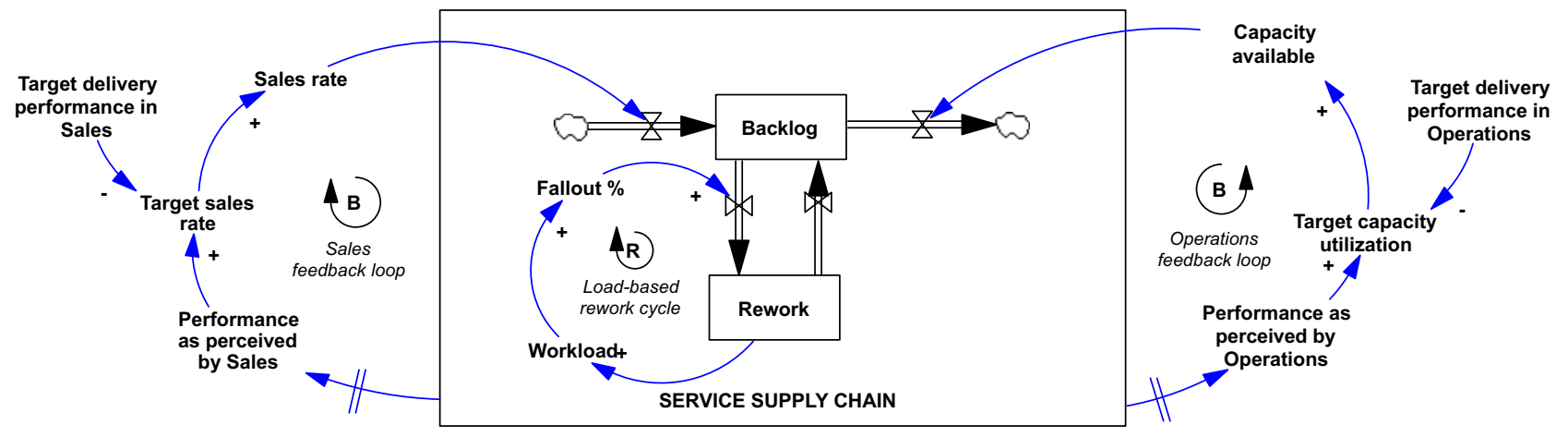

system dynamics models were developed. Based on these, to increase our understanding of the dynamics of the ramp up and ramp down processes, a generic model was developed that represents how the actions of the sales and operations functions in the service supply chain were linked, both causally and over time (see Figure 5).

In system dynamics, behavior over time is seen as the result of the dynamic interactions of two types of feedback loops: balancing loops that steer the system toward a certain goal or desired behavior and reinforcing feedback loops that steer the system toward a path of exponential growth or decline. The net result of all feedback loops determines the actual behavior of the system. Our model is comprised of three interacting feedback loops - two balancing (B) and one reinforcing (R). Examining the underlying causal structure that generates the complex dynamics observed, it is apparent that both ramp ups and ramp down decisions are the consequences of the same balancing loops that overshoot.

The first balancing loop is in sales, whose aim is to set the target sales rate as high as possible without compromising service delivery performance. The sales rate is adjusted based on performance data. However, there are lags in assessing current delivery performance as it takes time for orders to travel through the service supply chain and for information about delivery delays, fallout rates, and so on to travel back to sales and to confirm with sufficient certainty that the perceived performance is a trend and not just a random signal. Finally, there are implementation delays in translating the new understanding into revised policies-maintaining, increasing, or reducing the level of sales (Sterman, 2000). It is these delays that lead to an overshoot.

The second balancing loop is in operations, where the objective is to optimize capacity utilization without compromising delivery performance. As in sales, acquiring and processing the required information are subject to several delays. For example, it can be difficult to determine how much capacity is required for a given volume of incoming orders. As many processes are digital, significant capacity may be required for dealing with problems and rework, but the extent of the rework depends on the quality of the orders rather than their volume (Akkermans \& Vos, 2003). Thus, it takes time to establish when corrective action is needed; the corrective action (hiring and training extra staff) also takes time, as does evaluating the adequacy of that corrective action. Again, these delays can lead to an overshoot. Between these two balancing loops, a third, but reinforcing loop is concerned with rework. Fallout leads to rework, which increases workload to address the problems. How well the service performs will be determined by this rework cycle (Oliva \& Sterman, 2001).

"It is important to understand the relationship between operational and marketing processes and outcomes because, logically, operational success is an essential precondition to market success" (Tatikonda \& Montoya-Weiss, 2001, p. 152). Our empirical data indicate opposing decision biases in marketing and operations. Decision biases are systematic deviations in decision-making (Bendoly, Croson \& Goncalves, 2010). In operations, the observed policy of maximizing rather than optimizing capacity utilization in the context of high uncertainty and the high market cost of failing to fulfill customer needs can be viewed as decision bias. In marketing, performance measurement-driven pressure for rapid growth, prompting a willingness to ignore ongoing technical problems and capacity considerations in favor of ambitious ramp ups, can also be viewed as decision bias. These decision biases thus reflect a misalignment between targets. Figure 5 indicates these biases in targets will lead to higher sales 
rates and lower capacity availability than is needed, which in turn will lead to higher backlogs. As the model predicts, establishing when action is needed, taking corrective action, and assessing the adequacy of actions taken all took time, creating a strong amplification of the issues in both functions. Delays and a lack of information made addressing this more difficult. In addition, for both the sales and operations feedback loops, the rework cycle loop further complicated decisions and performance. Contributing to this were temporary fixes and workarounds for problems compounded the need for capacity to solve the problems. This can (and did) exhibit a tipping point, where increasingly more orders can be processed relatively smoothly until a capacity threshold is passed. At that point, a vicious cycle was triggered, in which more rework led to higher workloads, leading to more errors and more temporary fixes, which led to further rework.

In less extreme ramp ups, or with less delay, decisions could be made to reduce sales targets. However, in all three cases here it was too late, and the only possible decision was to ramp down. Out-of-control feedback loops forced the company to ramp down to regain control of the process.

Because ramp ups require cross-functional coordination and good visibility of capacity and backlogs (Oliva \& Watson, 2011), the more complex the service, the more important these become and the more difficult they are to put in place. This was a major problem in case 2, and it proved problematic in the other cases, indicating that poor systems and lack of visibility can compound ramp up problems. Effective systems can help build synergies between marketing and operations. Such synergies are valuable when built on complementary resources (Harrison, Hitt, Hoskisson \& Ireland, 2001).

We conclude that the behavior of the three ramp ups and the consequent ramp downs can be understood from a system dynamics perspective. In particular, the system dynamics model shown in Figure 5 indicates the conditions under which ramp up overshoots will occur, ramp downs will occur, and the need to align target sales rates and target capacity utilization. We argue that the capacity strategy should be consistent with the complexity of the service and its supply chain and the technical uncertainty associated with the new service. It seems realistic to expect that many new services will be launched in beta, and capacity and resource decisions should take account of this. Finally, the model indicates that delays have a major impact on the capacity to deal with misalignments and problems.

\section{DISCUSSION}

The purpose of this research is to explore ramp ups in the context of digital services, with a focus on the understudied area of ramp downs. It is based on three cases in a narrow context, but from our analysis, we set out a more general base for understanding service ramp ups and ramp downs.

\section{Ramp up}

Deploying new services rapidly is increasingly important for competitiveness (Qiang, Voss \& Zhao, 2018); however, extant research shows that too rapid growth leads to negative outcomes (Sterman et al., 2007). Our research builds on this by exploring rapid growth in digital services and the precursors of and behavioral contributors to ramp up problems. Service ramp ups can be understood in two parts-pre- and postlaunch.

Prelaunch. Service ramp ups typically take place immediately after the NSD process. Because the service may be difficult to fully test before launch and due to competitive pressure, services may be ramped up early, before they are fully developed-launching in beta. However, launching services that are not fully developed and/or tested can negatively influence the ramp up process and outcomes (Mass \& Berkson, 1995). Thus, the key decision on when to ramp up will require explicit attention to trade-offs: launching too late - which may lead to loss of market share or first-mover advantage - and launching too earlywhich risks service failure. The decision to ramp up should also address whether all the resources needed, not just those directly associated with the service, but across the whole supply chain, are in place.

Postlaunch. Service ramp ups, unlike products, take place in the field. Thus, any problems with the service or its delivery will manifest themselves to customers. The speed of ramp up is a central issue. Although service systems do not necessarily ramp up rapidly, a context of high competitive pressures and the growing digitization of services can lead to planning ramp ups that are an order of magnitude faster than product ramp ups.

We identify in our cases a number of factors leading to ramping up too soon and/or too fast, though they may not be present in all service ramp ups. As with projects, pressure to ramp up soon and rapidly accentuates the risk of the planning fallacy (Buehler et al., 1994) - that is, planning optimistically and overlooking project risks. The risks associated with early ramp up include unforeseen technical problems, and lack of capacity and capability in the service delivery system. The risks associated with rapid ramp up can include growing faster than scalability constraints, failure to resolve technical and service design problems quickly, and an inability to rapidly resource problem-solving when needed (Morrison, 2015).

We observed in our cases a neglect and possible lack of understanding of scalability. Services' scalability can 
range from low to high (Boyer et al., 2001), and there are risks that this scalability can be assumed to be higher than it actually is. There is often an assumption that digital services can scale rapidly even when there are constraining factors (Hallowell, 2001). These issues may be compounded by lack of recognition of the full service supply chain. In addition, as the nature of the service may change over time, the scalability of the service as well as the supply chain must be considered.

How fast to ramp up is a decision to be taken at launch and involves decisions by marketing on sales rates and operations on capacities. These decisions also need reviewing regularly during ramp up. This requires transparency and appropriate data on capacities, backlogs, and order problems. As ramp ups take place in the field, they involve both sales/marketing and operations functions when making decisions about resources, ramp up speed, and ramp down. Tang (2010) contends that marketing and operations can coexist in harmony within a firm when the market condition is stable. However, he argues that when developing and launching new products and services quickly, operations groups may find it challenging to meet marketing's expectations because production cannot be changed quickly. Thus, in rapid ramp ups co-operations between marketing and operations can be expected to be challenging. Although they may have been accentuated here, we contend that there is a general potential for functional misalignments to occur in the context of rapid service ramp ups. First, there may be differences in team culture. Second, performance measures for operations and marketing may be not aligned. For example, we observed an aggressive sales policy and a conservative capacity policy in our cases. In a service ramp up where capacity is uncertain, a potential dilemma for operations managers is whether to aim high and potentially incur cost penalties or adopt a conservative approach and risk building up insufficient capacity. These misalignments derive in part from the specific organization, but they also reflect the broader cultures associated with marketing, operations, and other functional specialisms, and as such, they are perhaps less easily changed. In ramp ups, functional decision biases can lead to misalignment, worsening cycles of delay, and backlogs. Thus, particularly in rapid ramp ups, there is a need for firms to manage potential conflict between marketing and operations. Our system dynamics model indicates how this conflict can lead to escalating feedback loops and failure to react effectively to problems. Out-of-control feedback loops lead to conditions requiring ramp down.

Ramp ups can be a common process in service firms, so learning is needed to avoid mistakes and improve processes (Pisano, 1996). Learning in complex, dynamic systems with significant feedback delays and accumulations in contexts such as this are problematic (Bendoly et al., 2010). As projects get more complicated, managers stop learning from their experience and fall into an "experience trap" using simplified heuristics developed from earlier, simpler contexts (Sengupta, Abdel-Habid \& van Wassenhove, 2008). Hall and Johnson-Hall (2017) argue that in product recall, the learning derived from failures can reduce the potential for future recalls. We would expect a similar pattern in ramp downs.

\section{Ramp down}

A key finding from this research was the importance and nature of ramp downs. In ramp ups, problems are likely to occur, particularly if launched in beta and with rapid ramp ups. Delays or failure to resolve problems leads to the possibility of the need to ramp down, cutting back or even stopping sales and delivery of the service and/or canceling existing orders. We have learned four things about ramp downs.

The Conditions Triggering the Need for a Ramp Down and Their Precursors. There are parallels between the processes of service ramp down and product recall. The conditions for both are when there are potentially significant costs arising from not ramping down or recalling (Hora et al., 2011). In services, these are direct costs, loss of revenue, and indirect costs, such as impact on brand image and market value. We identified multiple precursors of the need to ramp down. In addition to those that influence recalls, such as operational issues and actions that influence the quality of the product (Wowak \& Boone, 2015), there are those distinctive to service ramp downs. We observed many in our research: services launched in beta, leading to design problems remaining to be solved during ramp up; having inadequate resources to address problems, leading to delays in acquiring resources and addressing problems (Morrison, 2015); ramping up with inadequate attention to scaling the supply chain, leading to logistics and delivery problems; inadequate planning for the nature and scope of the service, which can lead to delays in service delivery; and finally solving problems by the use of improvisational means, such as workarounds, which may delay real problem-solving (Gross, 2014). Other precursors are possible; for example, Qiang et al. (2018) report a case where too late a ramp up led to ramp down as the service was obsolete by the time it was deployed.

Delay is a Key Issue in Ramping Down. Delays are an important concern in both product recalls (Wowak \& Boone, 2015) and service ramp downs. However, if problems are identified and addressed rapidly, they may not lead to the need to ramp down or the degree 
of ramping down could be less severe. In our study, the time from launch to ramp down was in the range of 11-32 weeks (Table 1). Hora et al. (2011) and Ni and Huang (2017) report substantial concern about delays in product recall decisions; for example, in a product recall of toys, the average time to recall ranged from 463 to 869 days and in automakers from 5.78 to 16.29 months. This substantial difference between products and services could be due to products being fully tested prior to launch and further problems only being identified after substantial use, while for digital services, a fast ramp up would lead to problems being identified much more rapidly. We observed that in rapid ramp ups, delays in addressing problems can result in a tipping point where a cycle of higher workloads leads to more errors and more temporary fixes, leading to further problems. This in turn has implications for capacity strategy in digital services, since the bulk of the human capacity required is often rework, depending on the quality of orders, more than their quantity (Akkermans \& Voss, 2013).

Causes of Ramp down Delay. In rapid ramp ups, delays in information and decision-making can seriously delay adjustments in ramp ups and decisions to ramp down. The model in Figure 5 indicates that corrective action will only be taken once the function recognizes a performance problem. In all cases, considerable time elapsed before sales grasped what was happening in the field and could decide what to do. Rapid response requires both capturing the appropriate information, for example, backlogs and complaints, and to have systems for capturing it early. Today, monitoring social media is increasingly effective for rapid forewarning of problems.

Management behavior can be a cause of delays. Optimism bias may lead to assumptions that problems can be solved rapidly and permanently and thus delaying decision-making. Consistent with outcomes observed in the cases, Meyer (2014) found that inproject optimism bias contributed significantly to decision makers' motivation to continue with a failing project. Moreover, ramping down may not be an easy decision to make. First, with aggressive target-setting linked to sales (as in this case), where marketing and sales personnel are financially incentivized, a ramp down can have a negative financial effect at the personal level. Second, there is significant institutional investment in a major ramp up, and ramp down entails a loss of face, internally and potentially externally. Face-saving is associated with behavior that protects an individual's self-esteem and that of others (Scheff, 1988). An inability to meet the standards of social norms or values results in a loss of face for the individual (Young, 2014). These factors may bias organizations toward delaying ramp down decisions.
Mitigating Ramp up Problems. A further issue identified in product recalls is mitigation approaches (Wowak \& Boone, 2015). While we did not collect data on this, there is a substantial field of study on mitigation approaches in services - service recovery. There are choices in service recovery including whether apologies should be pro-active or reactive and whether and where recompense should be given. The effectiveness and choices of service recovery strategies are contingent on context (Mattila, 2001); thus, there is a need for exploring these in the context of ramp downs.

Our research argues for extension of the scope of theories of NSD. Extant research sees the process as being completed prior to ramp up: "the process of devising a new or improved service, from idea or concept generation to market launch" (Biemans, Griffin \& Moenaert, 2016; p. 2). Menor et al. (2002) see the endpoint of NSD as a full launch. Consequently, that ramp up takes place at the end of the NSD process has either been ignored or seen as nonproblematic. Successful exploitation of service innovations requires attention to their deployment (Qiang et al., 2018). We argue that theories of service innovation and NSD should be extended to include the processes of deployment and ramping up.

The rapidly changing business environment raises the question, what are the future implications of this research? Technology evolution has increased the complexity of the service context by multiplying the ways customers can interact with other customers and different service providers, leading to complex service networks (Karmarkar, Kim \& Rhim, 2015; Patricio, Gustafsson \& Fisk, 2018). We contend that these trends will accentuate the issues that we have identified in service ramp ups. However, increasing learning and awareness of the need to manage service supply chains and experience in ramping up in digital services may counter this.

\section{CONCLUSIONS}

This research contributes to our understanding of service ramp ups and ramp downs. First, it proposes both similarities and differences between service and product ramp ups. Second, it elaborates a sequential model of the service ramp up process and identifies and explores key decisions, problems, and their causes. A distinctive contribution is the identification and exploration of the ramp down phenomenon. We identify reasons for the need to ramp down, their antecedents and in particular identify delays as a key issue and explore their potential causes.

The research has limitations. First, the empirical data were collected in one company and technical context, which limits the generalizability of the results. Other 
contexts may exhibit different or additional issues and behaviors. Second, such cases risk bias by the researcher and need validation in different contexts. Third, some of the issues identified ex post were strongly related to management behavior and Ball et al. (2018) call for research into behavioral aspects of the decision to recall. More in-depth methods are needed to build on these insights, such as whether company-level behavior would influence our findings. The research was conducted in the context of digital services; thus, a question arises as to its wider generalizability to nondigital service contexts. At first glance, the problems in the three cases could be viewed simply as examples of bad management. However, we argue that, although the observed problems may be worse than in many ramp ups, they reflect the multiple potential causes of service ramp up and ramp down problems.

Our findings provide implications for practice. To avoid falling into ramp up traps, ideally, ramping up should occur only after successful testing; however, the reality of competitive pressure and technical understanding means that many organizations will opt to launch in beta. They must manage the balance between ensuring the product is right, the market pressures to launch quickly, and investment in agile capacity to deal with potential technical issues. They require effective sales and operations planning systems to ensure transparency and minimize information delays as well as to coordinate planning in both functions. To avoid delayed ramp down decisions, companies need early warning signals and a fast and effective process to ramp down in a timely, controlled manner when required.

Managers must understand the context of their service and how it will influence scalability and constrain ramp up speed; particularly in digital services, they should be wary of assumptions of "infinite scalability." These are challenges for many organizations, owing to the optimism and cognitive biases that affect decision-making and the technical and market uncertainty inherent in such ramp ups.

With the growth of services in a highly competitive environment, implementing ramp ups effectively and avoiding costly ramp downs will be increasingly important for long-term success. Promising directions for further research include exploring the interaction of the factors and decisions associated with service ramp ups, and extending research to other empirical settings to understand how service ramp ups and ramp downs vary with context. The use of system dynamics models and simulations can contribute to this. There is scope for examining the learning processes, behavioral aspects, the decision biases, and assumptions that inform the management of service ramp ups and ramp downs.

\section{REFERENCES}

Agrella, P. J., Lindroth, R., \& Andreas Norrman, A. (2004). Risk, information and incentives in telecom supply chains. International Journal of Production Economics, 90, 1-16. https://doi.org/10.1016/ S0925-5273(02)00471-1

Åhlström, P., \& Karlsson, C. (2016). Longitudinal field studies. In C. Karlsson (Ed.), Research methods for operations management (pp. 198-232). London, UK: Routledge.

Akkermans, H. A., \& Vos, B. (2003). Amplification in service supply chains: An exploratory case study from the telecom industry. Production and Operations Management, 12, 204-223.

Akkermans, H. A., \& Voss, C. A. (2013). The service bullwhip effect. International Journal of Production and Operations Management, 33, 765-788.

Alter, C. (2014). Sebelius: Obamacare Rollout Was "Terribly Flawed." Retrieved from http://time.c om/61395/kathleen-sebelius-obamacare-rollout, accessed May 142018 https://doi.org/10.1111/ deci. 12163

Baines, T. (2015). Exploring service innovation and the servitization of the manufacturing firm. Research-Technology Management, 58, 9-11.

Ball, G. P., Shah, R., \& Donohue, K. (2018). The decision to recall: A behavioral investigation in the medical device industry. Journal of Operations Management, 62, 1-15.

Barratt, M., Choi, T., \& Li, M. (2011). Qualitative case studies in operations management: Trends, research outcomes and future research implications. Journal of Operations Management, 29, 329-342.

Baumard, P., \& Starbuck, W. H. (2005). Learning from failures: Why it may not happen. Long Range Planning, 38, 281-298.

Bendoly, E., Croson, R., \& Goncalves, P. (2010). Bodies of knowledge for research in behavioral operations. Production and Operations Management, 19, 434-435.

Biemans, W. G., Griffin, A., \& Moenaert, R. K. (2016). New service development: How the field developed, its current status and recommendations for moving the field forward. Journal of Product Innovation, Management, 33, 382-397.

Boyer, K., Hallowell, R., \& Roth, A. (2001). E-services: Operating strategy - A case study and a method for analyzing operational benefits. Journal of Operations Management, 20, 175-188.

Brauner, P., Philipsen, R., Fels, A., Fuhrmann, M., Ngo, Q. H. A. O., Stiller, S., Schmitt, R., \& Ziefle, M. (2016). A game-based approach to raise quality awareness in ramp up processes. Quality Management Journal, 23, 55-69.

Buehler, R., Griffin, D., \& Ross, M. (1994). Exploring the "planning fallacy": Why people underestimate their task completion times. Journal of Personality and Social Psychology, 67, 366-381.

Canon, M. D., \& Edmonson, A. C. (2005). Failing to learn and learning to fail (intelligently). Long Range Planning, 38, 299-319. 
Clark, K. B., \& Fujimoto, T. M. (1991). Product development performance: Strategy, organization, and management in the world auto industry. Cambridge, MA: Harvard Business School Press.

Finnegan, N. (2013). Retrieved from www.computer worlduk.com/news/it-business/349434/npower-ca lls-in-service-partners-after-troubled-sap-rollout-dis rupts-billing-systems/

Gross, U. (2014). Fighting the fire: Improvisational behavior during the production launch of new products. International Journal of Operations and Production Management, 34, 722-749.

Hall, D. C., \& Johnson-Hall, T. D. (2017). Learning from conformance quality failures that triggered product recalls: The role of direct and indirect experience. Journal of Supply Chain Management, $53,13-36$.

Hallowell, R. (2001). "Scalability": The paradox of human resources in e-commerce. International Journal of Service Industry Management, 12, 34-43.

Harrison, J. S., Hitt, M. A., Hoskisson, R. E., \& Ireland, R. D. (2001). Resource complementarity in business combinations: Extending the logic to organizational alliances. Journal of Management, 27, 679-690.

Heine, I., Beaujean, P., \& Schmitt, R. (2016). Improving production ramp up through human resource methods. Quality Management Journal, 23, 7-19.

Hora, M., Bapuji, H., \& Roth, A. V. (2011). Safety hazard and time to recall: The role of recall strategy, product defect type, and supply chain player in the U.S. toy industry. Journal of Operations Management, 29, 766-777.

Insights, B. (2017). A review of optimism bias, planning fallacy, sunk cost bias and groupthink in project delivery and organisational decision making. London, UK: Behavioural Insights Ltd.

Karlsson, C. (2016). Clinical management research. In C. Karlsson (Ed.), Research methods for operations management (pp. 268-289). London, UK: Routledge.

Karmarkar, U. S., Kim, K., \& Rhim, H. (2015). Industrialization, productivity and the shift to services and information. Production and Operations Management, 24, 1675-1695.

Ketokivi, M., \& Choi, T. (2014). Renaissance of case research as a scientific method. Journal of Operations Management, 32, 232-240.

Lenfle, S., \& Midler, C. (2009). The launch of innovative product-related services: Lessons from automotive telematics. Research Policy, 38, 156-169.

Li, H.-H. J. K., Shia, Y. S., Gregory, M., \& Tan, K. H. (2014). Rapid production ramp up capability: A collaborative supply network perspective. International Journal of Production Research, 52, 29993013.

Mass, N., \& Berkson, B. (1995). Going slow to go fast. McKinsey Quarterly, 4, 19-29.

Mattila, A. N. (2001). The effectiveness of service recovery in a multi-industry setting. Journal of Services Marketing, 15, 583-596.
Maull, R., Geraldi, J., \& Johnston, R. (2012). Service supply chains: A customer perspective. Journal of Supply Chain Management, 48, 72-86.

McKinsey \& Co. (2015). Digital America: A tale of the haves and have-mores. New York, NY: McKinsey Global Institute.

Menor, L. J., Tatikonda, M. V., \& Sampson, S. E. (2002). New service development: Areas for exploitation and exploration. Journal of Operations Management, 20, 135-157.

Meyer, W. G. (2014). The effect of optimism bias on the decision to terminate failing projects. Project Management Journal, 45, 7-20.

Morrison, B. (2015). The problem with workarounds is that they work: The persistence of resource shortages. Journal of Operations Management, 3940, 79-91.

Ni, J., \& Huang, X. (2017). Discovery-to-recall in the automotive industry: A problem-solving perspective on investigation of quality failures. Journal of Supply Chain Management, 54, 71-95.

Oliva, R., \& Sterman, J. D. (2001). Cutting corners and working overtime: Quality erosion in the service industry. Management Science, 47, 894914.

Oliva, R., \& Watson, N. (2011). Cross-functional alignment in supply chain planning: A case study of sales and operations supply planning. Journal of Operations Management, 29, 434-448.

Patricio, L., Gustafsson, A., \& Fisk, R. (2018). Upframing service design and innovation for research impact. Journal of Service Research, 21, 3-16.

Pisano, G. (1996). The development factory: Unlocking the potential of process innovation. Boston, MA: Harvard Business School Press.

Qiang, W., Voss, C. A., \& Zhao, X. (2018). Deployment strategies for service innovation. IEEE Transactions on Engineering Management, 99, 15.

Rössler, M. (2016). Ramp-up management. Retrieved from http://www.controlling.rwth-aachen.de

Sampson, S. E., \& Spring, M. (2012). Service supply chains: Introducing the special topic forum. Journal of Supply Chain Management, 48, 23-27.

Scheff, T. J. (1988). Shame and conformity: The deference-emotion system. American Sociological Review, 53, 395-406.

Schein, E. (1987). The clinical perspective in fieldwork: Professional and ethical issues in clinical versus ethnographic work. Newbury Park, NY: Sage publications.

Schneider, J., \& Hall, J. (2011). Why most product launches fail. Harvard Business Review, 39, 21-23.

Schoenherr, T., \& Swink, M. (2015). The roles of supply chain intelligence and adaptability in new product launch success. Decision Science, 46, 901-936.

Selviaridis, K., \& Norrman, A. (2014). Performancebased contracting in service supply chains. Supply Chain Management: An International Journal, 19, 153-172.

Sengupta, K., Abdel-Habid, T. K., \& van Wassenhove, L. N. (2008). The experience trap. How managers 
stop learning from experience. Harvard Business Review, 86, 94-101.

Sterman, J. D. (2000). Business dynamics: Systems thinking and modeling for a complex world. New York, NY: McGraw-Hill.

Sterman, J. D., Henderson, R., Beinhocker, E. D., \& Newman, L. I. (2007). Getting big too fast: Strategic dynamics with increasing returns and bounded rationality. Management Science, 53, 683-696.

Tang, C. S. (2010). A review of marketing-operations interface models: From co-existence to coordination and collaboration. International Journal of Production Economics, 125, 22-40.

Tatikonda, M. V., \& Montoya-Weiss, M. M. (2001). Integrating operations and marketing perspectives of product innovation: The influence of organizational process factors and capabilities on development performance. Management Science, 47, 151172.

Terweisch, C., Bohn, R. E., \& Chew, K. S. (2001). International product transfer and production ramp up. $R \& D$ Management, 31, 435-451.

Van de Ven, A. (2007). Engaged scholarship: A guide for organizational and social research. Oxford, UK: Oxford University Press.

Vennix, J. A. M. (1996). Group model-building: Facilitating team learning using system dynamics. Chichester, UK: Wiley.

Voss, C., Johnson, M., \& Godsell, J. (2016). Case research in operations management. In C. Karlsson (Ed.), Research methods for operations management (pp. 165-197). London, UK: Routledge.

Wowak, K. D., \& Boone, C. A. (2015). So many recalls, so little research: A review of the literature and road map for future research. Journal of Supply Chain Management, 51, 54-72.

Wynstra, J. Y. F., Axelsson, B., \& van der Valk, W. (2006). An application-based classification to understand buyer-supplier interaction in business services. International Journal of Service Industry Management, 17, 474-496.

Young, M. (2014). The formation of concern for face and its impact on knowledge sharing intention in knowledge management systems. Knowledge Management Research and Practice, 12, 36-47.

Zomerdijk, L. G., \& Voss, C. A. (2011). NSD processes and practices in experiential services. Journal of Product Innovation Management, 28, 63-80.

Henk Akkermans (Ph.D. TU Eindhoven, 1995) is Professor of Supply Chain Management, Department of Management at Tilburg School of Economics and Management, Tilburg University. His research addresses the issue of how interorganizational supply chains and networks, where no single party exerts full control, can nevertheless effectively coordinate their behavior. His focus is on technical, innovation-driven sectors (such as electronics, aerospace, telecom and process industry), but also on health care and public infrastructure. Henk Akkermans is fundamentally interested in the interactions between shop floor operations and customer demand, and in the roles that management information and cognitive limitations in decision-making play in this. His interest stretches all the way from new product/service development to maintenance and asset management activities. In order to obtain deeper insight in these complex issues, he develops system dynamics simulation models of real-world settings.

Chris Voss (Ph.D., London Business School) is a Professor of Operations Management, at the Warwick Business School, Warwick University. His research interests include, Service Management, Service Operations and Operations Strategy. His research accolades include: Journal of Service Research, 2010, Best Operations Management Paper Production and Operations Society, 2010 - awarded Lifetime Achievement Award, for contributions to service operations management Academy of Management - Elected 2008 Distinguished Scholar by the Operations Management Division Fellow of: European Operations Management Association, Production and Operations Society, Decision Science Institute, British Academy of Management.

Roeland van Oers (M.Sc/Drs. Maastricht University) is the director of WELBO in The Netherlands. His current research interests lie in the area of human robot interaction, social robots, supply chain networks, organizational learning.

\section{SUPPORTING INFORMATION}

Additional supplemental material may be found online in the Supporting Information section at the end of the article:

Appendix S1. Data Collection and Analysis.

\section{APPENDIX IN-CASE RESULTS}

To address RQ2 and RQ3, we examine the individual ramp ups in more detail.

Case 1: Consumer Voice over Internet Protocol (VOIP). At the outset, management held the view that a cautious rollout should be planned. Initially, no advance orders were taken. Once the service was publicly launched, there were ten times the expected orders, leading to a high level of outstanding orders early in the process. After some delay, the supply network was 
able to adapt to the higher volume, and installations kept pace with the still moderate level of sales. However, there were many technical problems during this period-for example, customers would lose the use of their previous service before the new one had been installed, and there were complaints about intermittent service.

Customer groups were segmented by level of technical complexity; to begin, marketing focused only on the easy customer segments. Around week 20, this approach was abandoned, and a major ramp up began (see Figure 2). The number of customers with connection problems grew rapidly, with an everincreasing number of complaints as more customers contacted the helpdesk. At the same time, the company became increasingly worried about its fulfillment capability, leading eventually to the recruitment of 300 extra technicians to help customers with home installations. In addition, an extra team was formed to deal with complex complaints on an individual basis. A new installation package was developed that was easier for customers to use. In week 42, as helpdesk calls peaked, the top management team broke out the Champagne to celebrate record sales. Soon afterward, the problems were publicized on TV and social media, and by week 60 , both complaints and negative media coverage had peaked. Sales were scaled down to allow existing consumer problems to be effectively addressed, and by week 65 , these were running at pre-ramp up levels. Once sales had been ramped down, there was a period of consolidation to allow technical problems to be fully resolved before gradual recovery in activation.

Case 2: Fiber-based broadband services. Reflecting on the problems in case 1 , the management team decided to create a more thorough sales and operations planning process to regulate the speed of rollout, taking account of both central capacity and local constraints such as a shortage of engineers. The service was initially tested on a number of friendly users and then in a first local pilot. The explicit strategy was to increase sales, but slowly and with a degree of restraint. However, even in the early stages, there were both pressures for and expectations of rapid ramp up once the initial technical problems had been addressed:

We started selling fiber even though the supply network was not finished. We cannot wait for the supply network to function. We then believed the supply network would go live very quickly. (Case 2, Marketing manager)

In both alpha and beta phases, orders were being taken ahead of ramp up. During beta, all services (Internet, TV, and Voice) worked, but there were still activation problems. Problem-solving and learning continued, with increasing use of workarounds for cases that had not been solved by software releases. Despite growing evidence of technical delays, marketing continued to contract new customers. At the same time, the pressure to deliver ambitious ramp up goals remained and even intensified. As shown in Figure 3, orders contracted remained steady during the first 15 weeks, but the level of activated orders remained very low, causing the backlog to escalate rapidly. Around week 15, the ramp up accelerated, and sales efforts were substantially increased.

There is an aggressive conversion campaign for the existing customer base. We have targets for sales and cost per order, and it is our job to sell as many orders as possible against the lowest cost-that's our mission.

(Case 2, Fiber director)

While the weekly rate of contracted customers increased strongly, customer activation rates continued to lag considerably behind. Technical problems persisted, and capacity issues continued to emerge. By week 35, management had realized that the backlog of customers waiting to be activated had become too large, lead times were too long, and levels of quality problems and complaints were too high. The decision was made to scale back drastically on sales, and order intake was stopped for all but one customer group. Subsequently, technical in-service problems were stabilized, and a steadier and more effective ramp up followed.

Case 3: Business VOIP. Following consumer VOIP, the company launched a business VOIP service. Management had learned from the problems with preceding launches that a cautious rollout should be planned. Learning from cases 1 and 2, there was an extended initial (alpha) testing period with 100 friendly users (see Figure 4). This extended testing identified numerous flaws in the IT system, and every order required manual rework, which resulted in the installation of a new IT system. This was followed by a beta evaluation of service robustness. Once the initial technical problems had been addressed, advance orders again began to be taken, allowing a small back$\log$ to develop. In week 40 , a very ambitious ramp up was launched in full.

Estimates for the ramp up vary between 60 to 160 times the current volume through the service supply chain. Historically, such a steep ramp up is not uncommon. (Case 3, External consultant)

However, although the initial problems had been solved by means of manual fixes and workarounds, these did not translate into high-order volumes. In addition, problems surfaced in parts of the supply chain that were not involved in the early careful testing, such as external partners, billing, and technical 
operations. Having to execute workarounds for large numbers of orders proved very difficult, in terms of both resources required and ongoing fundamental problems. As a result, the activation rate remained very low, and within ten weeks, a massive backlog had developed, leading in turn to a substantial rise in order cancelations. In response, the sales effort was drastically scaled down until these problems could be resolved. One third of backlogged orders were canceled, and once the problems had been effectively addressed, the launch continued with a more modest ramp up. 